Article

\title{
Vanadium Oxide Supported on MSU-1 as a Highly Active Catalyst for Dehydrogenation of Isobutane with $\mathrm{CO}_{2}$
}

\author{
Guosong Sun ${ }^{1,2, *}$, Qingze Huang ${ }^{2}$, Shiyong Huang ${ }^{2}$, Qiuping Wang ${ }^{2}$, Huiquan $\mathrm{Li}^{3}$, \\ Haitao Liu ${ }^{3}$, Shijie Wan ${ }^{4}$, Xuewang Zhang ${ }^{2}$ and Jinshu Wang ${ }^{1, *}$ \\ 1 The College of Materials Science and Engineering, Beijing University of Technology, Beijing 100022, China \\ 2 Guangxi Research Institute of Chemical Industry, Nanning 530001, China; huang0823@126.com (Q.H.); \\ shiyonghuang@163.com (S.H.); wangqiuping8287@163.com (Q.W.); zxw507@163.com (X.Z.) \\ 3 Key Laboratory for Green Process and Engineering, Institute of Process Engineering, Chinese Academy of \\ Sciences, Beijing 100190, China; hqli@home.ipe.ac.cn (H.L.); liuht@home.ipe.ac.cn (H.L.) \\ 4 Guangxi Branch of China Academy of Science \& Technology Development, Nanning 530001, China; \\ wanshijie01@126.com \\ * Correspondence: sungsgx@163.com (G.S.); wangjsh@bjut.edu.cn (J.W.); Tel.: +86-77-1330-6235 (G.S.); \\ +86-10-6739-1101 (J.W.); Fax: +86-77-1331-5527 (G.S.); +86-10-6739-1101 (J.W.)
}

Academic Editor: Michalis Konsolakis

Received: 12 January 2016; Accepted: 7 March 2016; Published: 9 March 2016

\begin{abstract}
Vanadium oxide supported on MSU-1, with $\mathrm{VO}_{x}$ loading ranging from 2.5 to 17.5 wt. \%, was developed as a highly active catalyst in dehydrogenation of isobutane with $\mathrm{CO}_{2}$. The obtained catalysts of $\mathrm{VO}_{x} / \mathrm{MSU}-1$ were characterized by X-ray diffraction (XRD), $\mathrm{N}_{2}$ adsorption-desorption, and $\mathrm{H}_{2}$-temperature programmed reduction $\left(\mathrm{H}_{2}\right.$-TPR) methods and the results showed that the large surface area of MSU-1 was favorable for the dispersion of $\mathrm{VO}_{x}$ species and the optimal loading of $\mathrm{VO}_{x}$ was $12.0 \mathrm{wt}$ \%. Meanwhile, the catalytic activity of $\mathrm{VO}_{x} / \mathrm{MSU}-1$ was investigated, and $\mathrm{VO}_{x} / \mathrm{MSU}-1$ with 12.0 wt. $\% \mathrm{VO}_{x}$ content was found to be the best one, with the conversion of isobutane $(58.8 \%)$ and the selectivity of isobutene $(78.5 \%)$ under the optimal reaction conditions. In contrast with the reaction in the absence of $\mathrm{CO}_{2}$, the presence of $\mathrm{CO}_{2}$ in the reaction stream could obviously enhance the isobutane dehydrogenation, which raised the conversion of reaction and the stability of $\mathrm{VO}_{\mathrm{x}} / \mathrm{MSU}-1$.
\end{abstract}

Keywords: $\mathrm{VO}_{x} / \mathrm{MSU}-1$ catalyst; isobutane; dehydrogenation; isobutene; $\mathrm{CO}_{2}$

\section{Introduction}

Dehydrogenation of lower alkanes to alkenes is always attractive research around the world [1-4]. With the use of downstream products of isobutene increasing [5,6], the demand of isobutene is rapidly growing, so the dehydrogenation of isobutane to isobutene is becoming one of the important ways to produce isobutene. The process of dehydrogenation can be classified into two types: direct dehydrogenation and oxidative dehydrogenation. In fact, the direct dehydrogenation of isobutane to isobutene has been achieved in industrialization [7], but there are still some serious technical problems, such as high production cost, complex processing, and deactivation of the catalyst by carbon deposition. As a result, the oxidative dehydrogenation of isobutane (ODB) has received more and more attention, recently [8,9]. ODB will not be limited by thermodynamic equilibrium, so the conversion of isobutane can obviously be raised and the energy consumption can be greatly reduced. Due to the deep oxidation of product, there is lower isobutene selectivity using oxygen $\left(\mathrm{O}_{2}\right)$ as an oxidant $[10,11]$. Recently, $\mathrm{CO}_{2}$ has received much attention as a co-feed gas for dehydrogenation, because $\mathrm{CO}_{2}$ can act as a mild oxidant [12-15]. Unlike oxygen, $\mathrm{CO}_{2}$ will not be able to fully oxidize the catalyst to its original state due to its weak oxidation capacity. It is a thermodynamically stable and a kinetically inert molecule, 
and it is also cheap and abundant. Moreover, because of its high heat capacity, using $\mathrm{CO}_{2}$ as a co-feed can alleviate the effects of the exothermal ODB reaction, avoiding hot spots that can lead to cracking of the alkane [14,16]. It has been confirmed that $\mathrm{CO}_{2}$ had the ability to partially refresh active species on the catalysts and participated in the oxidative dehydrogenation [17]. When $\mathrm{CO}_{2}$ was present in the feed, the reaction followed the oxidative dehydrogenation route but was also accompanied by the reverse water gas shift (RWGS) reaction in combination with the direct dehydrogenation route $[17,18]$. Moreover, $\mathrm{CO}_{2}$ can eliminate coke deposited over the catalysts, to some extent, and improve the stability of catalysts [19]. Therefore, in recent years, the research of dehydrogenation of isobutane with $\mathrm{CO}_{2}$ has been actively studied, which mainly focused on the development of different catalysts.

The catalysts containing vanadium were found to have excellent catalytic activity for the dehydrogenation reaction [20-25]. Ogonowski et al. [24] loaded vanadium oxides on active carbon (AC), $\mathrm{SiO}_{2}, \mathrm{Al}_{2} \mathrm{O}_{3}$, and $\mathrm{ZnO}$, and found that the key factor influencing catalytic activity was the alkalinity / acidity of catalyst surface and oxidation-reduction potential of vanadium species. Research of Ma et al. [25] on $\mathrm{V}_{2} \mathrm{O}_{5} / \mathrm{Al}_{2} \mathrm{O}_{3}$ and $\mathrm{V}_{2} \mathrm{O}_{5} / \mathrm{SiO}_{2}$ catalyst showed that vanadium species with higher dispersion had better catalytic activity. However, the traditional carriers, such as $\mathrm{Al}_{2} \mathrm{O}_{3}$ and $\mathrm{SiO}_{2}$, possessed low specific surface area, small pore size and wide pore size distribution, which restricted the activity of catalysts. In view of these, mesoporous materials used as the carrier were widely studied. MSU- $x$ is an important family of mesoporous material, with 3D worm-like holes, which possess many advantages of pore structure and is in favor of the diffusion of molecular objects [26]. Furthermore, the non-ionic surfactants used as templates in the synthesis of MSU- $x$ materials are low-cost, non-toxic, and biodegradable; thus, it is more suitable for the carriers of catalysts. In the early work of our group, the catalysts had been prepared by loading chromium on MSU- $x$ for catalytic dehydrogenation of propane and ethane [27-30], which had showed high catalytic activity.

In this paper, MSU-1, was prepared at room temperature using sodium silicate as the source of silicon. Then, vanadium oxide, $\mathrm{VO}_{x}$, was loaded over the carrier of MSU-1 and a series of vanadium-based catalysts, $\mathrm{VO}_{x} / \mathrm{MSU}-1$, were prepared by wet impregnation method. The obtained catalysts were characterized with X-ray diffraction (XRD), $\mathrm{N}_{2}$ adsorption-desorption, and $\mathrm{H}_{2}$-temperature programmed reduction $\left(\mathrm{H}_{2}\right.$-TPR) techniques. The catalytic performance of $\mathrm{VO}_{x} / \mathrm{MSU}-1$ was investigated for the dehydrogenation of isobutane with or without $\mathrm{CO}_{2}$.

\section{Results and Discussion}

\subsection{Catalyst Characterization}

Figure 1 showed XRD patterns of the samples prepared, including undoped and $\mathrm{VO}_{x}$-modified MSU-1 ( $\mathrm{VO}_{x} / \mathrm{MSU}-1$ ) in two different regions of $2 \theta$ angle, where they were $0.5^{\circ}-10^{\circ}$ and $10^{\circ}-85^{\circ}$. In the $2 \theta$ range of $0.5^{\circ}-10^{\circ}$, one well-resolved diffraction peak was observed (Figure $1 \mathrm{~A}$ ), which corresponded to $\mathrm{d}_{100}$ reflection [31]. This result clearly indicated that they all had the typically less long-range-ordered, worm-like mesoporous structure. Compared with undoped MSU-1, the intensity of diffraction peak of $\mathrm{VO}_{x}$-containing MSU-1 gradually decreased with $\mathrm{VO}_{x}$ content increasing. However, even in the case of MSU-1 with the highest $\mathrm{VO}_{x}$ loading, $17.5 \mathrm{wt}$ \% , the $\mathrm{d}_{100}$ diffraction peak were still obviously observed, indicating that the mesoporous structure of the catalysts, $\mathrm{VO}_{x} / \mathrm{MSU}-1$, remained well during impregnation and subsequent calcination.

According to the large-angle XRD patterns of $10^{\circ}-85^{\circ}$ (Figure 1B), it could be seen that the diffraction peaks corresponding to crystal phase of $\mathrm{V}_{2} \mathrm{O}_{5}$ were $15.5^{\circ}, 20.2^{\circ}, 26.2^{\circ}$, and $31.1^{\circ}$. However, these peaks were absent for the samples with $\mathrm{VO}_{x}$ loading lower than $12.0 \mathrm{wt}$. \%. This could be attributed to high dispersion of crystal phase of bulk $\mathrm{V}_{2} \mathrm{O}_{5}$ on the surface of MSU-1. When $\mathrm{VO}_{x}$ loading reached $17.5 \mathrm{wt}$. \%, the peaks became very clear, which indicated that more and larger crystal phase of bulk $\mathrm{V}_{2} \mathrm{O}_{5}$ appeared over MSU- 1 with the increase of $\mathrm{VO}_{x}$ loading. The catalytic activity and selectivity of vanadium oxide for oxidative dehydrogenation depended on its structure, dispersion, and the characteristics of its supporting material. The most active catalytic form for this type of reaction 
was the monomeric, isolated $\mathrm{VO}_{x}$ species [32]. The presence of bulk $\mathrm{V}_{2} \mathrm{O}_{5}$ on the other hand decreased the selectivity and favored total oxidation. So, the fit $\mathrm{VO}_{x}$ loading for $\mathrm{VO}_{x} / \mathrm{MSU}-1$ catalysts should be $12.0 \mathrm{wt}$. \% or so.
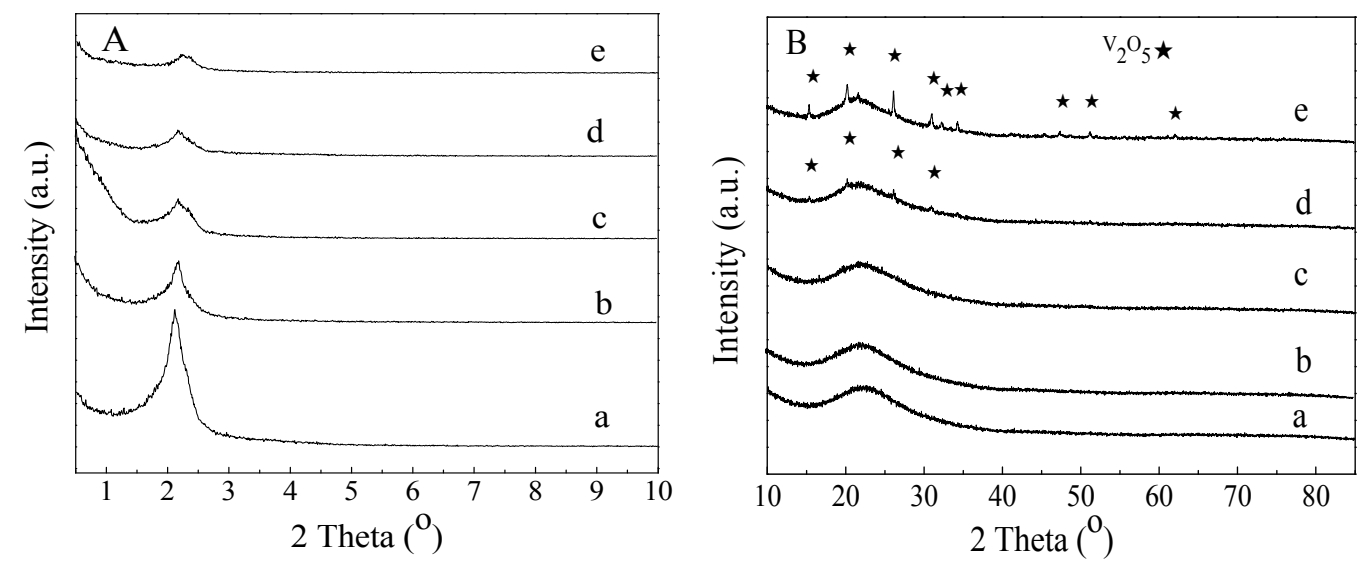

Figure 1. X-ray diffraction (XRD) patterns of MSU-1 and $\mathrm{VO}_{x} / \mathrm{MSU}-1$ with different $\mathrm{VO}_{x}$ loading. (A) $2 \theta$ in the range of $0.5^{\circ}-10^{\circ}$; (B) $2 \theta$ in the range of $10^{\circ}-85^{\circ}$. (a) MSU-1; (b) $2.5 \mathrm{wt}$. $\%$ VO $x$ /MSU-1; (c) 7.0 wt. \% $\mathrm{VO}_{x} / \mathrm{MSU}-1$; (d) 12.0 wt. \% $\mathrm{VO}_{x} / \mathrm{MSU}-1$; and (e) 17.5 wt. \% $\mathrm{VO}_{x} / \mathrm{MSU}-1$.

Table 1 listed Brunauer-Emmett-Teller (BET) surface area and pore volume of undoped and $\mathrm{VO}_{x}$-modified MSU-1. From Table 1, it could be seen that the carrier of MSU-1 possessed high-surface area $\left(1021.3 \mathrm{~m}^{2} / \mathrm{g}\right)$ and moderate pore volume $\left(0.54 \mathrm{~cm}^{3} / \mathrm{g}\right)$, which was favorable for the dispersion of active components. As for $\mathrm{VO}_{x} / \mathrm{MSU}-1$ samples, both surface area and pore volume decreased gradually with $\mathrm{VO}_{x}$ content increasing in comparison to MSU-1. This could be due to that more $\mathrm{VO}_{x}$ loading led to the formation of larger $\mathrm{VO}_{x}$ crystals and as a result, a certain amount of MSU-1 pores was blocked by the bulk crystals, which was also confirmed by XRD patterns of $\mathrm{VO}_{x} / \mathrm{MSU}-1$ samples (Figure 1). When $\mathrm{VO}_{x}$ loading was $17.5 \mathrm{wt} . \%$, the surface area and pore volume of $\mathrm{VO}_{x}$ /MSU-1 decreased to $297.9 \mathrm{~m}^{2} / \mathrm{g}$ and $0.30 \mathrm{~cm}^{3} / \mathrm{g}$, respectively, which was not advantageous to the dehydrogenation of isobutane.

Table 1. Physical properties of MSU- 1 and $\mathrm{VO}_{x} / \mathrm{MSU}-1$ with different $\mathrm{VO}_{x}$ loading.

\begin{tabular}{ccc}
\hline Samples & BET Surface Area $\left(\mathbf{m}^{2} / \mathbf{g}\right)$ & Pore Volume $\left(\mathbf{c m}^{3} / \mathbf{g}\right)$ \\
\hline MSU-1 & 1021.3 & 0.54 \\
2.5 wt. $\% \mathrm{VO}_{x} / \mathrm{MSU}-1$ & 748.4 & 0.40 \\
7.0 wt. $\% \mathrm{VO}_{x} / \mathrm{MSU}-1$ & 655.7 & 0.33 \\
12.0 wt. $\% \mathrm{VO}_{x} / \mathrm{MSU}-1$ & 539.4 & 0.34 \\
17.5 wt. $\% \mathrm{VO}_{x} / \mathrm{MSU}-1$ & 297.9 & 0.30 \\
\hline
\end{tabular}

The pore diameter distribution of different samples was shown in Figure 2, which was determined by Barrett-Joyner-Halenda (BJH) method. As shown in Figure 2, the peak at $2.2 \mathrm{~nm}$ was attributed to the characteristic behavior of mesoporous materials MSU-1, and the pore size distribution was narrow and normal, indicating that the carrier of MSU-1 had a uniform pore structure. Moreover, with $\mathrm{VO}_{x}$ content increasing, the peak shape gradually moved to the left, as a whole, and the width of peak also increased in the meantime. When $\mathrm{VO}_{x}$ loading reached $17.5 \mathrm{wt}$. \%, the peak had moved to $1.8 \mathrm{~nm}$ from $2.2 \mathrm{~nm}$, which suggested that some pores of MSU-1 might be partly occupied by vanadium oxides, resulting in smaller pore size. As a result, the pore size distribution of $\mathrm{VO}_{x} / \mathrm{MSU}-1$ catalysts were broadened and the surface area and pore volume were decreased. 


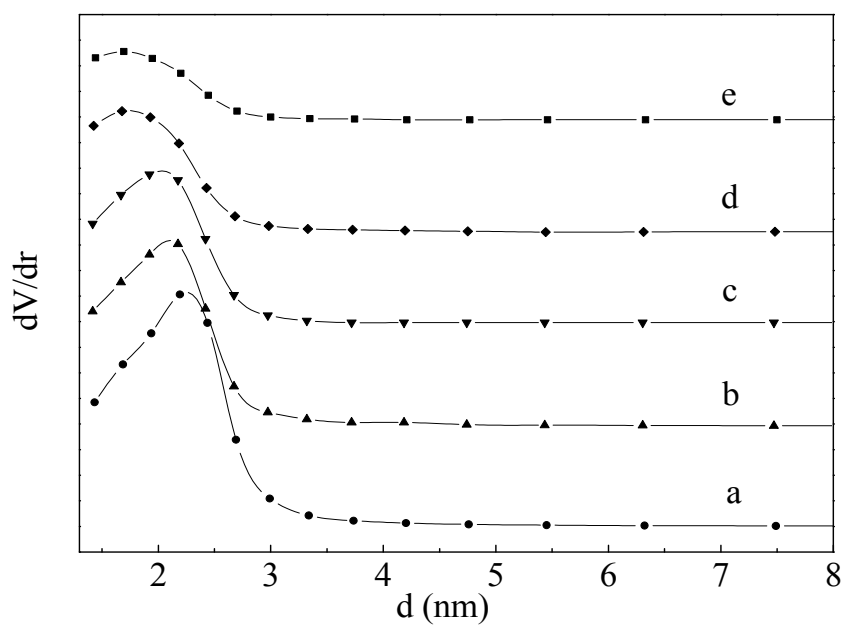

Figure 2. Pore diameter distribution of MSU-1 and $\mathrm{VO}_{x} / \mathrm{MSU}-1$ with different $\mathrm{VO}_{x}$ loading. (a) MSU-1; (b) 2.5 wt. \% VO $/$ MSU-1; (c) 7.0 wt. \% VO $/$ MSU-1; (d) 12.0 wt. \% VO $/$ MSU-1; and (e) $17.5 \mathrm{VO}_{x} / \mathrm{MSU}-1$.

$\mathrm{H}_{2}$-TPR patterns of undoped MSU-1 and $\mathrm{VO}_{x} / \mathrm{MSU}-1$ catalysts with different $\mathrm{VO}_{x}$ loading were comparatively shown in Figure 3. There were no $\mathrm{H}_{2}$ consumption peaks to be found for undoped MSU-1 in Figure 3. For the samples containing 2.5-12.0 wt. \% $\mathrm{VO}_{x}$, a weak reduction peak at $680-720 \mathrm{~K}$ were observed, in which vanadium species existed mainly in the form of surface oligo-species with the octahedral coordination [33]. TPR curves of all $\mathrm{VO}_{x}$-supported samples, $\mathrm{VO}_{x}$ loading from $2.5 \mathrm{wt}$. \% to $17.0 \mathrm{wt}$ \%, exhibited one strong reduction peak in the temperature range of $820-850 \mathrm{~K}$, which was found to shift to higher temperatures as the $\mathrm{VO}_{x}$ loading was increased, suggesting increased particle size of microcrystalline vanadia with loading. This has been confirmed that as the vanadia species became more bulk-like, i.e., the particle size increased with an increase in loading, the vanadia became more difficult to reduce due to bulk diffusion limitations resulting in a shift in TPR peaks to higher temperatures [33,34]. The samples, containing more than $7.0 \mathrm{wt}$ \% $\mathrm{VO}_{x}$ were characterized by new peaks appearing already between 920 and $970 \mathrm{~K}$, which gradually increased with $\mathrm{VO}_{x}$ loading, showing that more bulk-like $\mathrm{VO}_{x}$ crystals had been shaped. This had been concluded that there was a correlation between the reducibility of surface vanadium species and their catalytic properties. High activity was ascribed to vanadate species, either isolated or polymerized up to the formation of a $\mathrm{VO}_{x}$ monolayer, whereas lower activity was usually associated with the presence of bulk $\mathrm{V}_{2} \mathrm{O}_{5}[34,35]$.

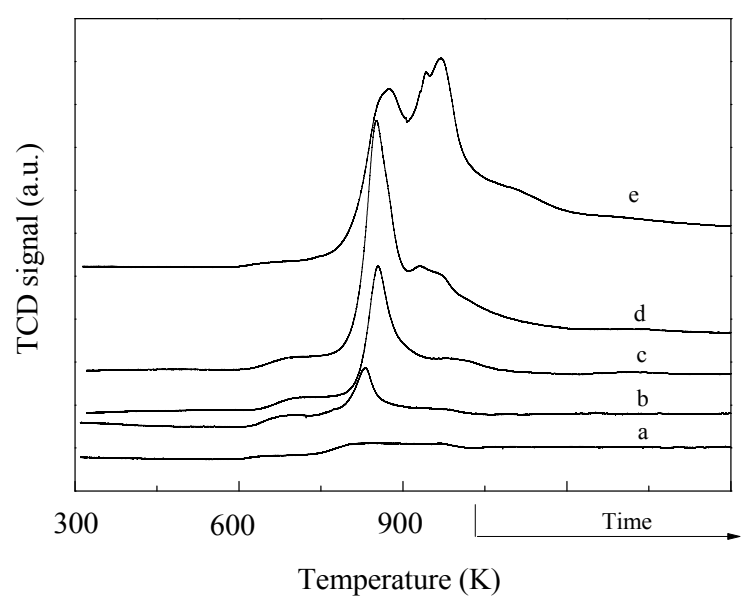

Figure 3. $\mathrm{H}_{2}$-temperature programmed reduction $\left(\mathrm{H}_{2}\right.$-TPR) profiles of MSU-1 and $\mathrm{VO}_{x} / \mathrm{MSU}-1$ with different $\mathrm{VO}_{x}$ loading. (a) MSU-1; (b) 2.5 wt. \% $\mathrm{VO}_{x} / \mathrm{MSU}-1$; (c) 7.0 wt. \% $\mathrm{VO}_{x} / \mathrm{MSU}-1$; (d) 12.0 wt. $\% \mathrm{VO}_{x} / \mathrm{MSU}-1$; and (e) 17.5 wt. \% $\mathrm{VO}_{x} / \mathrm{MSU}-1$. 


\subsection{Catalytic Performance}

The catalytic performance of $\mathrm{VO}_{x} / \mathrm{MSU}-1$ with different $\mathrm{VO}_{x}$ loading for the isobutane dehydrogenation were shown in Table 2, where the main byproducts of reaction were also listed out, including propylene $\left(\mathrm{C}_{3} \mathrm{H}_{6}\right)$ and methane $\left(\mathrm{CH}_{4}\right)$. Undoped MSU-1 exhibited low catalytic activity in comparison to $\mathrm{VO}_{x}$-doped samples, with $11.8 \%$ conversion of isobutane $\left(i-\mathrm{C}_{4} \mathrm{H}_{10}\right)$ and $52.5 \%$ selectivity of isobutene $\left(i-\mathrm{C}_{4} \mathrm{H}_{8}\right)$ (Entry 1$)$. The conversion of isobutane gradually increased with $\mathrm{VO}_{x}$ loading, and reached maximum value, $58.8 \%$ (Entry 4 ), when $\mathrm{VO}_{x}$ loading was $12 \mathrm{wt}$. \%. While $\mathrm{VO}_{x}$ loading further increased to $17.5 \mathrm{wt}$. \%, the conversion of isobutane begun to decrease to $51.0 \%$ (Entry 6). This could be due to that more $\mathrm{VO}_{x}$ loading resulted in the poor dispersion of $\mathrm{VO}_{x}$ species and formation of more bulk-like $\mathrm{VO}_{x}$ crystals, which had been demonstrated by XRD (Figure 1) and $\mathrm{H}_{2}$-TPR (Figure 3) characterization. However, the selectivity of isobutene did not exhibit obvious change in a certain extent with the increase of $\mathrm{VO}_{x}$ loading, basically keeping at $79 \%$ or so. The selectivity of main byproducts, propylene and methane, also remained stable in principle, approximately $10 \%$ and $5 \%$, respectively. Moreover, contrasting Entries 4 and 5 in Table 2, it could be found that the presence of $\mathrm{CO}_{2}$ significantly enhanced the efficiency of isobutane dehydrogenation, which was generally attributed to that $\mathrm{CO}_{2}$ as a weak oxidant could eliminate hydrogen produced during the dehydrogenation through RWGS reaction $[18,36]$. Coupling of RWGS reaction with the dehydrogenation reaction therefore improved the equilibrium conversion of reaction toward isobutene production. In Table 2, with $\mathrm{CO}_{2}$ conversion increasing, the conversion of isobutane gradually increased, which further confirmed the role of $\mathrm{CO}_{2}$ coupling reaction.

Table 2. Catalytic performance for isobutane dehydrogenation over $\mathrm{VO}_{x} / \mathrm{MSU}-1$ with different $\mathrm{VO}_{x}$ loading.

\begin{tabular}{cccccccc}
\hline \multirow{2}{*}{ Entry } & \multirow{2}{*}{$\begin{array}{c}\text { VO } \\
\text { (wt. } \text { Loading }\end{array}$} & \multicolumn{2}{c}{ Conversion (\%) } & \multicolumn{3}{c}{ Selectivity (\%) } & Yield (\%) \\
\cline { 3 - 7 } & $\mathbf{i}-\mathbf{C}_{\mathbf{4}} \mathbf{H}_{\mathbf{1 0}}$ & $\mathbf{C O}_{\mathbf{2}}$ & $\boldsymbol{i}-\mathbf{C}_{\mathbf{4}} \mathbf{H}_{\mathbf{8}}$ & $\mathbf{C}_{\mathbf{3}} \mathbf{H}_{\mathbf{6}}$ & $\mathbf{C H}_{\mathbf{4}}$ & $\boldsymbol{i}-\mathbf{C}_{\mathbf{4}} \mathbf{H}_{\mathbf{8}}$ \\
\hline 1 & 0 & 11.8 & 0.6 & 52.5 & 30.2 & 13.6 & 6.2 \\
2 & 2.5 & 36.3 & 7.7 & 79.5 & 9.6 & 4.6 & 28.9 \\
3 & 7.0 & 54.9 & 14.8 & 79.2 & 9.4 & 4.7 & 43.5 \\
4 & 12.0 & 58.8 & 16.9 & 78.5 & 9.9 & 5.4 & 46.2 \\
5 & $12.0^{*}$ & 40.5 & $/$ & 82.8 & 10.5 & 6.6 & 33.5 \\
6 & 17.5 & 51.0 & 15.2 & 78.9 & 9.8 & 5.6 & 40.2 \\
\hline Reaction conditions: reaction temperature $873 \mathrm{~K}$, total flow rate $24 \mathrm{~mL} /$ min, catalyst $0.2 \mathrm{~g}, \mathrm{~V}\left(\mathrm{CO}_{2}\right): \mathrm{V}\left(i-\mathrm{C}_{4} \mathrm{H}_{10}\right)=3: 1 ;$ \\
${ }^{*} \mathrm{~V}(\mathrm{Ar}): \mathrm{V}\left(i-\mathrm{C}_{\mathbf{4}} \mathrm{H}_{10}\right)=3: 1$.
\end{tabular}

The effect of temperature on the dehydrogenation of isobutane with $\mathrm{CO}_{2}$ were shown in Figure 4, using $12 \mathrm{wt}$ \% $\mathrm{VO}_{x} / \mathrm{MSU}-1$ as catalyst. The conversion of isobutane gradually increased as the reaction temperature was raised, whereas the selectivity of isobutene, the object product, decreased on the contrary. Although high temperature could accelerate the dehydrogenation rate of isobutane, meanwhile the elevation of temperature favored cracking of isobutane to produce propylene and methane. So, considering all reaction factors, $873 \mathrm{~K}$ was chosen as the optimal reaction temperature, with the conversion of isobutane $58.8 \%$ and the selectivity of isobutene $78.5 \%$.

Figure 5 exhibited the catalytic activity of $12 \mathrm{wt}$. \% $\mathrm{VO}_{x} / \mathrm{MSU}-1$ as a function of reaction time. As the reaction proceeded, the isobutane conversion of dehydrogenation gave a visible drop, either in the presence of or in the absence of $\mathrm{CO}_{2}$, suggesting that the catalyst was deactivated to some degree. In contrast with the reaction in the absence of $\mathrm{CO}_{2}$, the presence of $\mathrm{CO}_{2}$ in the reaction stream here could obviously enhance the stability of $\mathrm{VO}_{x} / \mathrm{MSU}-1$, and the drop rate of isobutane conversion with $\mathrm{CO}_{2}$ was lower than that without $\mathrm{CO}_{2}$. For example, the conversion of isobutane decreased from primal $58.8 \%$ to $44.2 \%$ with $\mathrm{CO}_{2}$ and $40.5 \%$ to $21.9 \%$ without $\mathrm{CO}_{2}$, respectively, after reacting for $3 \mathrm{~h}$. This was due to that $\mathrm{CO}_{2}$ in the reaction stream could suppress the formation of coke deposited over $\mathrm{VO}_{x} /$ MSU-1 $[17,37,38]$. Moreover, from Figure 5, it could also be seen that the selectivity to isobutene gave a slight increase with proceeding reaction, especially with $\mathrm{CO}_{2}$. 


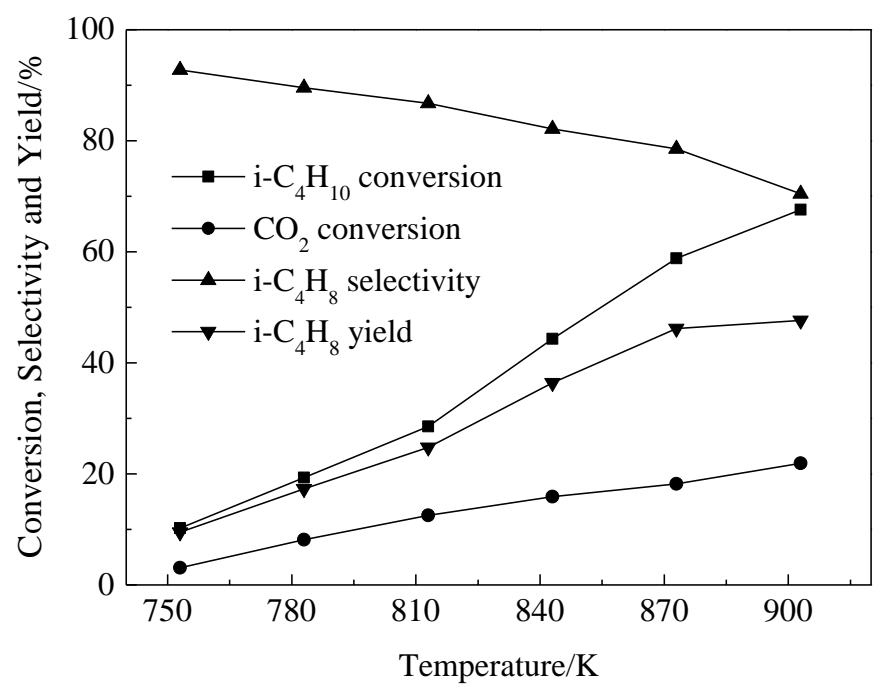

Figure 4. Effect of temperature on dehydrogenation of isobutane to isobutene with $\mathrm{CO}_{2}$ over $\mathrm{VO}_{x} / \mathrm{MSU}-1$. Reaction conditions: $12 \mathrm{wt}$. $\% \mathrm{VO}_{x} / \mathrm{MSU}-10.2 \mathrm{~g}$; total flow rate $24 \mathrm{~mL} / \mathrm{min}$; $\mathrm{V}\left(\mathrm{CO}_{2}\right): \mathrm{V}\left(i-\mathrm{C}_{4} \mathrm{H}_{10}\right)=3: 1$.

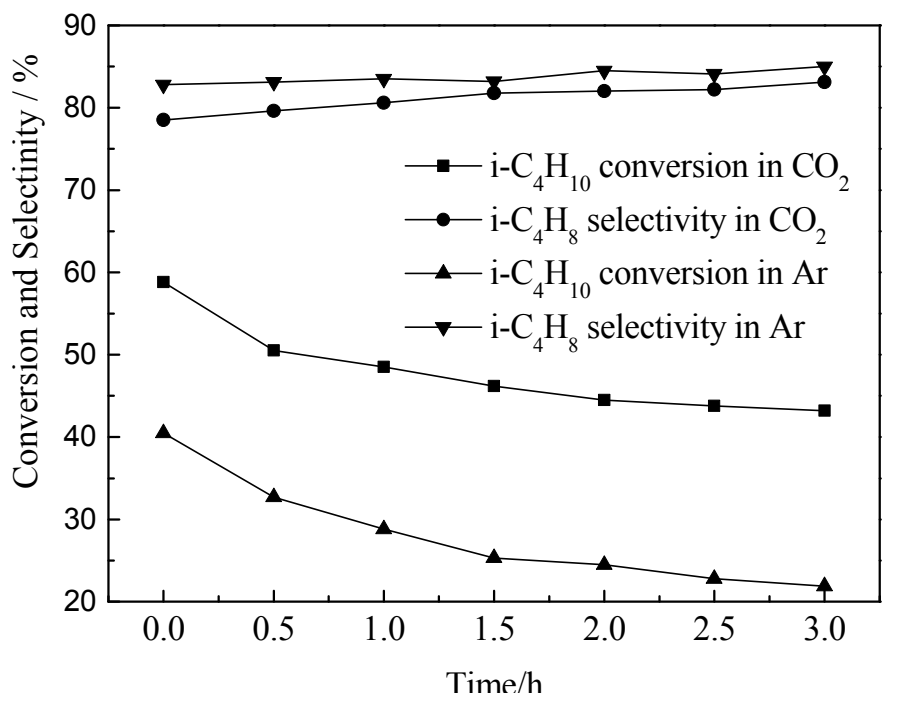

Figure 5. Catalytic stability in dehydrogenation of isobutane to isobutene with $\mathrm{CO}_{2}$ or $\mathrm{Ar}$ over $\mathrm{VO}_{x} / \mathrm{MSU}-1$. Reaction conditions: reaction temperature $873 \mathrm{~K}$, total flow rate $24 \mathrm{~mL} / \mathrm{min}$, 12 wt. $\% \mathrm{VO}_{x} / \mathrm{MSU}-10.2 \mathrm{~g}, \mathrm{~V}\left(\mathrm{CO}_{2}\right): \mathrm{V}\left(i-\mathrm{C}_{4} \mathrm{H}_{10}\right)=3: 1$ or $\mathrm{V}(\mathrm{Ar}): \mathrm{V}\left(i-\mathrm{C}_{4} \mathrm{H}_{10}\right)=3: 1$.

\section{Experimental Section}

\subsection{Catalyst Preparation}

The carrier of MSU-1 was prepared at room temperature using sodium silicate as the source of silicon by the method reported before [22,23]. All the catalysts of $\mathrm{VO}_{x} / \mathrm{MSU}-1$ were prepared by wet impregnation method. Typically, $2 \mathrm{~g}$ of dry MSU-1 was treated with $20 \mathrm{~mL}$ of aqueous solution containing the desired amount of $\mathrm{NH}_{4} \mathrm{VO}_{3}$ (analytically pure) overnight. The impregnated samples were evaporated and dried at $353 \mathrm{~K}$ for $7 \mathrm{~h}$ and finally calcined under air at $873 \mathrm{~K}$ for $4 \mathrm{~h}$. These catalysts are designated as $x$ wt. $\% \mathrm{VO}_{x} / \mathrm{MSU}-1$, where $x$ expresses the total $\mathrm{VO}_{x}$ loading. 


\subsection{Catalyst Characterization}

XRD patterns were recorded in two ranges of $0.5^{\circ}-10.0^{\circ}$ and $10^{\circ}-85^{\circ}(2 \theta)$ at room temperature, using X'pert Pro MPD X-ray diffractometer from PANalytical (Almelo, Holland) operated at $40 \mathrm{kV}$ and $30 \mathrm{~mA}$, equipped with a $\mathrm{Cu} K \alpha \mathrm{X}$-ray source.

$\mathrm{N}_{2}$ adsorption-desorption measurements were carried out on an Autosorb series ASIMP apparatus from Quantachrome (Boynton Beach, FL, USA). Before measurements, the samples were degassed at $573 \mathrm{~K}$ under vacuum for $3 \mathrm{~h}$. Calculation of specific surface area (BET), pore volume and pore size distribution (BJH method) were performed with the software of the apparatus.

$\mathrm{H}_{2}$-TPR analysis (self-made experimental instrument) were performed using $\mathrm{Ar} / \mathrm{H}_{2}$ gas mixture ( $95 / 5 \mathrm{vol} \%)$. The total flow rate of the feed was $30 \mathrm{~mL} / \mathrm{min}$. Before experiment the sample $(100 \mathrm{mg})$ was preheated in a stream of dry argon at $873 \mathrm{~K}$ for $30 \mathrm{~min}$, and then cooled to room temperature. The samples were heated at $15 \mathrm{~K} / \mathrm{min}$ to the final temperature of $1073 \mathrm{~K} . \mathrm{H}_{2}$ consumption was measured by a thermal conductivity detector and $\mathrm{V}_{2} \mathrm{O}_{5}$ was used as a reference for the calibration of $\mathrm{H}_{2}$ consumption.

\subsection{Catalytic Tests}

The catalytic tests of isobutane dehydrogenation were carried out in a fixed-bed quartz tubular reactor with an inner diameter of $6.0 \mathrm{~mm}$ at 773-973 K and atmospheric pressure. For each test, about $0.2 \mathrm{~g}$ of catalyst sample (40-60 mesh) was diluted with quartz grain and loaded in the constant temperature zone of the reactor. The reaction stream was constituted of isobutane and $\mathrm{CO}_{2}$ or $\mathrm{Ar}$ with the mole ratio of $n\left(\mathrm{CO}_{2}\right) / n\left(\mathrm{C}_{4} \mathrm{H}_{10}\right)$ or $n(\mathrm{Ar}) / n\left(\mathrm{C}_{4} \mathrm{H}_{10}\right)$ being 3 and the total flow rate being $24 \mathrm{~mL} / \mathrm{min}$.

The reactants and products were analyzed on-line using a gas chromatograph (Shimadzu GC-2014,

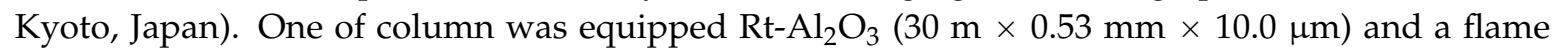
ionization detector. This column was used to analyze hydrocarbons $\mathrm{C}_{1}-\mathrm{C}_{4}$. The second column was equipped GDX-502 $(3 \mathrm{~m} \times 2 \mathrm{~mm})$ and a thermal conductivity detector for $\mathrm{CO}$ and $\mathrm{CO}_{2}$ analyses, which carrier gas is He. Conversion $(C)$ of isobutane and carbon dioxide and selectivity $(S)$ of isobutene and other byproducts were calculated according to the following equations:

$$
\begin{gathered}
C_{\mathrm{C}_{4} \mathrm{H}_{10}}=\frac{n_{\mathrm{C}_{4} \mathrm{H}_{8}}+\frac{3}{4} n_{\mathrm{C}_{3} \mathrm{H}_{8}}+\frac{3}{4} n_{\mathrm{C}_{3} \mathrm{H}_{6}}+\frac{1}{2} n_{\mathrm{C}_{2} \mathrm{H}_{6}}+\frac{1}{2} n_{\mathrm{C}_{2} \mathrm{H}_{4}}+\frac{1}{4} n_{\mathrm{CH}_{4}}}{n_{\mathrm{C}_{4} \mathrm{H}_{10}}+n_{\mathrm{C}_{4} \mathrm{H}_{8}}+\frac{3}{4} n_{\mathrm{C}_{3} \mathrm{H}_{8}}+\frac{3}{4} n_{\mathrm{C}_{3} \mathrm{H}_{6}}+\frac{1}{2} n_{\mathrm{C}_{2} \mathrm{H}_{6}}+\frac{1}{2} n_{\mathrm{C}_{2} \mathrm{H}_{4}}+\frac{1}{4} n_{\mathrm{CH}_{4}}} \times 100 \% \\
C_{\mathrm{CO}_{2}}=\frac{n_{\mathrm{CO}}}{n_{\mathrm{CO}}+n_{\mathrm{CO}_{2}}} \times 100 \% \\
S_{i}=\frac{\frac{a_{i}}{4} n_{i}}{n_{\mathrm{C}_{4} H_{8}}+\frac{3}{4} n_{\mathrm{C}_{3} H_{8}}+\frac{3}{4} n_{\mathrm{C}_{3} H_{6}}+\frac{1}{2} n_{\mathrm{C}_{2} H_{6}}+\frac{1}{2} n_{\mathrm{C}_{2} \mathrm{H}_{4}}+\frac{1}{4} n_{\mathrm{CH}_{4}}} \times 100 \%
\end{gathered}
$$

where $a_{i}$ was the number of carbon atoms of the compound $i$ and $n_{i}$ is the mole number of the compound $i$. The calculations did not consider the conversion of isobutane to coke.

\section{Conclusions}

In conclusion, the catalysts of $\mathrm{VO}_{x} / \mathrm{MSU}-1$, prepared by loading $\mathrm{VO}_{x}$ over MSU-1, were active and selective in the oxidative dehydrogenation of isobutane with $\mathrm{CO}_{2}$. Their catalytic properties were related to the $\mathrm{VO}_{x}$ loading and high surface area of MSU-1. XRD, $\mathrm{N}_{2}$ adsorption-desorption and $\mathrm{H}_{2}$-TPR characterization for $\mathrm{VO}_{x} /$ MSU-1 showed that the optimal loading of $\mathrm{VO}_{x}$ was $12.0 \mathrm{wt}$. $\%$ and more $\mathrm{VO}_{x}$ could led to the formation of larger bulk-like $\mathrm{VO}_{x}$ crystals and the decrease of the surface area and pore volume. As a result, $12.0 \mathrm{wt}$. $\% \mathrm{VO}_{x} / \mathrm{MSU}-1$ exhibited the highest catalytic activity, with the conversion of isobutane $58.8 \%$ and the selectivity of isobutene $78.5 \%$ at $873 \mathrm{~K}$. In the feed of reactants, the presence of $\mathrm{CO}_{2}$ played quite important role on the dehydrogenation of isobutane, 
which not only could remove $\mathrm{H}_{2}$ produced in the reaction through RWGS reaction but also suppress the formation of coke deposits and improve the stability of $\mathrm{VO}_{x} / \mathrm{MSU}-1$.

Acknowledgments: This work was supported by grants from the National Natural Science Foundation of China (No. 21006109) and the Guangxi Science Foundation of China (2012GXNSFBA053033 \& 2011GXNSFA018053).

Author Contributions: Guosong Sun and Jinshu Wang conceived and designed the experiments; Guosong Sun, Qingzhe Huang and Qiuping Wang performed the experiments; Shiyong Huang, Haitao Liu and Huiquan Li contributed to data analysis and discussion; Guosong Sun, Qingzhe Huang, Shiyong Huang and Jishu Wang wrote and revised the manuscript; Shijie Wan was responsible for supplementing the detailed role of $\mathrm{CO}_{2}$ during the reaction in the introduction; Xuewang Zhang contributed to the supplementary explanation of X-ray diffraction (XRD), $\mathrm{H}_{2}$-temperature programmed reduction $\left(\mathrm{H}_{2}\right.$-TPR) and other experimental data.

Conflicts of Interest: The authors declare no conflict of interest.

\section{References}

1. Wang, S.B.; Murata, K.; Hayakawa, T.; Hamakawa, S.; Suzuki, K. Dehydrogenation of ethane with carbon dioxide over supported chromium oxide catalysts. Appl. Catal. A 2000, 196, 1-8. [CrossRef]

2. Tasbihi, M.; Feyzi, F.; Amlashi, M.A.; Abdullah, A.Z.; Mohamed, A.R. Effect of the addition of potassium and lithium in Pt-Sn $/ \mathrm{Al}_{2} \mathrm{O}_{3}$ catalysts for the dehydrogenation of isobutane. Fuel Process. Technol. 2007, 88, 883-889. [CrossRef]

3. Wang, M.G.; Zhong, S.H. Pd $/ \mathrm{V}_{2} \mathrm{O}_{5}-\mathrm{SiO}_{2}$ catalyst for oxidative dehydrogenation of isobutane with $\mathrm{CO}_{2}$ to isobutene. Chin. J. Catal. 2007, 28, 124-130.

4. Rombi, E.; Gazzoli, D.; Cutrufello, M.G.; De Rossi, S.; Ferino, I. Modifications induced by potassium addition on chromia/alumina catalysts and their influence on the catalytic activity for the oxidative dehydrogenation of propane. Appl. Surf. Sci. 2010, 256, 5576-5580. [CrossRef]

5. Seddon, D. Reformulated gasoline, opportunities for new catalyst technology. Catal. Today 1992, 15, 1-21. [CrossRef]

6. Iannazzo, V.; Neri, G.; Galvagno, S.; Di Serio, M.; Tesser, R.; Santacesaria, E. Oxidative dehydrogenation of isobutane over $\mathrm{V}_{2} \mathrm{O}_{5}$-based catalysts prepared by grafting vanadyl alkoxides on $\mathrm{TiO}_{2}-\mathrm{SiO}_{2}$ supports. Appl. Catal. A 2003, 246, 49-68. [CrossRef]

7. Resasco, D.E.; Marcus, B.K.; Huang, C.S.; Durante, V.A. Isobutane dehydrogenation over sulfided nickel catalysts. J. Catal. 1994, 146, 40-55. [CrossRef]

8. De Rossi, S.; Ferraris, G.; Fremiotti, S.; Indovina, V.; Cimino, A. Isobutane dehydrogenation on chromia/zirconia catalysts. Appl. Catal. A 1993, 106, 125-141. [CrossRef]

9. Gniot, I.; Kirszensztejn, P.; Kozlowski, M. Oxidative dehydrogenation of isobutane using modified activated carbons as catalysts. Appl. Catal. A 2009, 362, 67-74. [CrossRef]

10. Zhang, L.; Deng, J.; Dai, H.; Au, C.T. Binary Cr-Mo oxide catalysts supported on MgO-coated polyhedral three-dimensional mesoporous SBA-16 for the oxidative dehydrogenation of iso-butane. Appl. Catal. A 2009, 354, 72-81. [CrossRef]

11. Neri, G.; Pistone, A.; De Rossi, S.; Rombi, E.; Milone, C.; Galvagno, S. Ca-doped chromium oxide catalysts supported on alumina for the oxidative dehydrogenation of isobutane. Appl. Catal. A 2004, 260, 75-86. [CrossRef]

12. Castro, A.J.R.; Soares, J.M.; Filho, J.M.; Oliveira, A.C.; Campos, A.; Milet, É.R.C. Oxidative dehydrogenation of ethylbenzene with $\mathrm{CO}_{2}$ for styrene production over porous iron-based catalysts. Fuel 2013, 108, 740-748. [CrossRef]

13. Chen, S.W.; Qin, Z.F.; Wang, G.F.; Dong, M.; Wang, J.G. Promoting effect of carbon dioxide on the dehydrogenation of ethylbenzene over silica-supported vanadium catalysts. Fuel 2013, 109, 43-48. [CrossRef]

14. Wu, R.; Xie, P.; Cheng, Y.; Yue, Y.; Gu, S.; Yang, W.; Miao, C.; Hua, W.; Gao, Z. Hydrothermally prepared $\mathrm{Cr}_{2} \mathrm{O}_{3}-\mathrm{ZrO}_{2}$ as a novel efficient catalyst for dehydrogenation of propane with $\mathrm{CO}_{2}$. Catal. Commun. 2013, 39, 20-23. [CrossRef]

15. Wang, S.; Zhu, Z.H. Catalytic conversion of alkanes to olefins by carbon dioxide oxidative dehydrogenation-a review. Energy Fuels 2004, 18, 1126-1139. [CrossRef] 
16. Ajayi, B.P.; Jermy, B.R.; Ogunronbi, K.E.; Abussaud, B.A.; Al-Khattaf, S. $n$-Butane dehydrogenation over mono and bimetallic MCM-41 catalysts under oxygen free atmosphere. Catal. Today 2013, 204, 189-196. [CrossRef]

17. Ascoop, I.; Galvita, V.V.; Alexopoulos, K.; Reyniers, M.; Van Der Voort, P.; Bliznuk c, V.; Marin, G.B. The role of $\mathrm{CO}_{2}$ in the dehydrogenation of propane over $\mathrm{WO}_{x}-\mathrm{VO}_{x} / \mathrm{SiO}_{2}$. J. Catal. 2016, 335, 1-10.

18. Ding, J.F.; Qin, Z.F.; Li, X.K.; Wang, G.F.; Wang, J.G. Catalytic dehydrogenation of isobutane in the presence of carbon dioxide over nickel supported on active carbon. J. Mol. Catal. A 2010, 315, 221-225. [CrossRef]

19. Ogonowski, J.; Skrzyńska, K. Carbon dioxide in the dehydrogenation of isobutane over $\mathrm{VMgO}_{x}$. Catal. Commun. 2009, 11, 132-136. [CrossRef]

20. Carrazán, S.R.G.; Peres, C.; Bernard, J.P.; Ruwet, M.; Ruiz, P.; Delmon, B. Catalytic synergy in the oxidative dehydrogenation of propane over MgVO catalysts. J. Catal. 1996, 158, 452-476. [CrossRef]

21. Takita, Y.; Xia, Q.; Kikutani, K.; Soda, K.; Takami, H.; Nishigushi, H.; Nagaoka, K. Anaerobic oxidation of isobutane: II. Catalysis by Mg-V complex oxides. J. Mol. Catal. A 2006, 248, 61-69. [CrossRef]

22. Fu, Y.; Ma, H.; Wang, Z.; Zhu, W.; Wu, T.; Wang, G. Characterization and reactivity of $\mathrm{SnO}_{2}$-doped $\mathrm{V}_{2} \mathrm{O}_{5} / \gamma-\mathrm{Al}_{2} \mathrm{O}_{3}$ catalysts in dehydrogenation of isobutane to isobutene. J. Mol. Catal. A 2004, 221, 163-168. [CrossRef]

23. Ogonowski, J.; Skrzyńska, E. Deactivation of $\mathrm{VMgO}_{x}$ catalysts by coke in the process of isobutane dehydrogenation with carbon dioxide. Catal. Lett. 2008, 121, 234-240. [CrossRef]

24. Ogonowski, J.; Skrzyńska, E. Activity of vanadium magnesium oxide supported catalysts in the dehydrogenation of isobutane. Catal. Lett. 2006, 111, 79-85. [CrossRef]

25. Ma, H.; Liu, Z.; Wang, Z.; Zhu, W.; Wang, G. Study of $\mathrm{V}_{2} \mathrm{O}_{5} / \gamma-\mathrm{Al}_{2} \mathrm{O}_{3}$ catalyst for dehydrogenation of isobutane. Chin. J. Appl. Chem. 2002, 19, 290-294.

26. Prouzet, É.; Boissière, C. A review on the synthesis, structure and applications in separation processes of mesoporous MSU- $x$ silica obtained with the two-step process. Comptes Rendus Chim. 2005, 8, 579-596. [CrossRef]

27. Liu, L.; Li, H.; Zhang, Y. A comparative study on catalytic performances of chromium incorporated and supported mesoporous MSU- $x$ catalysts for theoxidehydrogenation of ethane to ethylene with carbon dioxide. Catal. Today 2006, 115, 235-241. [CrossRef]

28. Liu, L.; Li, H.; Zhang, Y. Mesoporous silica-supported chromium catalyst: Characterization and excellent performance in dehydrogenation of propaneto propylene with carbon dioxide. Catal. Comm. 2007, 8, 565-570. [CrossRef]

29. Liu, H.; Li, H.; Yang, W.; Wang, X.; Zhang, Y. Effect of Cr content on catalytic performance of Cr/MSU-1 catalysts in oxidative dehydrogenation of propane to propylene with $\mathrm{CO}_{2}$. Acta Chim. Sin. 2009, 15, 1749-1753.

30. Liu, L.; Li, H.; Zhang, Y. Effect of synthesis parameters on the chromium content and catalytic activities of mesoporous Cr-MSU- $x$ prepared under acidic conditions. J. Phys. Chem. B 2006, 110, 15478-15485. [CrossRef] [PubMed]

31. Sierra, L.; Guth, J.L. Synthesis of mesoporous silica with tunable pore size from sodium silicate solutions and a polyethylene oxide surfactant. Micropor. Mesopor. Mater. 1999, 27, 243-253. [CrossRef]

32. Rossetti, I.; Fabbrini, L.; Ballarini, N.; Oliva, C.; Cavani, F.; Cericola, A.; Bonelli, B.; Piumetti, M.; Garrone, E.; Dyrbeck, $\mathrm{H}$.; et al. $\mathrm{V}_{2} \mathrm{O}_{5}-\mathrm{SiO}_{2}$ systems prepared by flame pyrolysis as catalysts for the oxidative dehydrogenation of propane. J. Catal. 2008, 256, 45-61. [CrossRef]

33. Koranne, M.M.; Goodwin, J.G.; Marcelin, G. Characterization of silica- and alumina-supported vanadia catalysts using temperature programmed reduction. J. Catal. 1994, 148, 369-377. [CrossRef]

34. Adamski, A.; Sojka, Z.; Dyrek, K. Surface heterogeneity of zirconia-supported $\mathrm{V}_{2} \mathrm{O}_{5}$ catalysts. The link between structure and catalytic properties in oxidative dehydrogenation of propane. Langmuir 1999, 15, 5733-5741. [CrossRef]

35. Deo, G.; Wachs, I.E. Reactivity of supported vanadium oxide catalysts: The partial oxidation of methanol. J. Catal. 1994, 146, 323-334. [CrossRef]

36. Ding, J.F.; Qin, Z.F.; Li, X.K.; Wang, G.F.; Wang, J.G. Coupling dehydrogenation of isobutane in the presence of carbon dioxide over chromium oxide supported on active carbon. Chin. Chem. Lett. 2008, 19, 1059-1062. [CrossRef] 
37. Gascón, J.; Téllez, C.; Herguido, J.; Menéndez, M. Propane dehydrogenation over a $\mathrm{Cr}_{2} \mathrm{O}_{3} / \mathrm{Al}_{2} \mathrm{O}_{3}$ catalyst: Transient kinetic modeling of propene and coke formation. Appl. Catal. A 2003, 248, 105-116. [CrossRef]

38. Shimada, H.; Akazawa, T.; Ikenaga, N.; Suzuki, T. Dehydrogenation of isobutane to isobutene with iron-loaded activated carbon catalyst. Appl. Catal. A 1998, 168, 243-250. [CrossRef]

(c) 2016 by the authors; licensee MDPI, Basel, Switzerland. This article is an open access article distributed under the terms and conditions of the Creative Commons by Attribution (CC-BY) license (http://creativecommons.org/licenses/by/4.0/). 